\title{
Determinants of adherence to iron-folic acid supplementation among postnatal mothers in Addis Ababa referral hospitals, Ethiopia
}

Tigist Alemu Taye ( $\nabla$ tigistalemutaye@gmail.com )

Ethiopian youth sports academy

Mesele Sinaga

Jimma university

Abonesh Taye

Jimma university

\section{Research Article}

Keywords: IFAS adherence, pregnant women, Addis Ababa, Ethiopia

Posted Date: June 4th, 2021

DOI: https://doi.org/10.21203/rs.3.rs-590351/v1

License: (c) (i) This work is licensed under a Creative Commons Attribution 4.0 International License.

Read Full License 


\section{Abstract}

Abstract: In Ethiopia, adherence to iron-folic acid supplementation is disappointingly low were only $5 \%$ took more than 90 tablets during their pregnancy; however, only limited data are available on the determinant factors of non-adherence. Therefore, the aim of this study was to identify determinants of adherence to iron-folic acid supplementation among postnatal mothers in three referral hospitals of Addis Ababa, Ethiopia.

\section{Purpose:}

Methods: An institutional based unmatched case-control study was conducted on 240 women who have been at postnatal care. Data were collected using interviewer administered questionnaire. Data were entered and analyzed using EpiData and SPSS version 20.0, respectively. Bivariate and multivariate logistic regressions were employed to identify the determinants at $p$-value $<0.25$ and $<0.05$ respectively.

Results: The major determinant factors of adherence to iron-folic acid supplementation were, mothers age group 29-33 [AOR=1.66, 95\% Cl: 2.010-0.0492], ANC initiation time [AOR=4.21, 95\% Cl: 2.3-10.6], counseling on IFAS [AOR=3.89,95\% Cl: 1.8-8.4], time taken to travel to health facility [AOR=3.17,95\% $\mathrm{Cl} 1.35-7.4]$, gravidity [AOR=2.08,95\% Cl:1.06-4.09], morning sickness [AOR 0.33, 95\% $\mathrm{Cl}: 0.15-0.69]$ and planned pregnancy $[\mathrm{AOR}=4.2,95 \% \mathrm{Cl}: 1.6-10.9]$.

Conclusion: This study highlighted age of participants, planned pregnancy, antenatal care initiation time, morning sickness, gravidity, counseling and distance to health facility are factors that have independently associate with adherence. Counseling should be given for clients on the correct dosage and duration of supplementation for prevention of anemia and neural tube defects.

\section{Introduction}

Subdermal Iron folic acid (IFA) adherence is the extent to which patients take medication or condition of sticking to dose and time for taking iron-folic acid supplement as prescribed by their health care providers or per recommendations. ${ }^{1}$ Women are said to be adhered to iron-folic acid supplement if they took 90 or more of the supplement. ${ }^{2}$

World Health Organization (WHO) recommends that all pregnant women receive a standard dose of 30$60 \mathrm{mg}$ iron and $400-\mu \mathrm{g}(0.4 \mathrm{mg})$ folic acid beginning as early as possible during gestation. Ideally, women should take 180 tablets before delivery; however, many countries, including, Ethiopia aim for women to receive $90+$ tablets during pregnancy. ${ }^{3}$

Studies conducted indifferent parts of the world have shown low adherence of women taking daily ironfolic acid supplementation. This is among one of the main reasons why IFAS programs have been less 
effective. $^{4}$

Several developing countries are now implementing iron-folic acid supplementation programs, but only a few countries significantly improved anemia control and prevention. According to the demographic health survey of 2008, adherence to iron-folic acid supplement by pregnant women in Kenya is low. Nationally only $2.5 \%$ of pregnant women take iron-folic acid supplement more than 90 days of the recommended 180 days. $^{5}$

Also in Ethiopia, IFAS is integral part of ANC and it is free of charge for pregnant women. However, effectiveness and success of such intervention depend on its adherence. Many experts believe that one of the main reasons that national IFAS program has failed is women's of "Non-Adherence". According to Ethiopia national data of EDHS, 2016 adherence to IFAS is disappointingly low as $58 \%$ of pregnant women don't took any tablets, $30 \%$ took $<60$ tablets and only $5 \%$ took $90+$ during their pregnancy. ${ }^{6}$

This indicates that identifying factors associated with adherence to IFAS is an important step to Material and methods improve the IFA tablets use among pregnant women in urban and rural areas of the country.

\section{Methods}

\section{Study design}

An institutional based unmatched case control study was conducted to identify the determinant factors of adherence to iron-folate supplementation among post-natal mothers in Addis Ababa referral hospitals, Ethiopia, 2020. Addis Ababa is the capital city of Ethiopia.

\section{Study area}

This study was conducted in three referral hospitals of Addis Ababa, namely Zewditu Memorial Hospital (ZMH), Palouse hospital and Gandhi Memorial Hospital (GMH). Addis Ababa is the capital city of Ethiopia. The latitude of Addis Ababa is 9.005401, and the longitude is 38.763611.7 Based on the 2017 population projection, the total Population of the city is $3,273,001$, among which $1,772,001$ are women and 1,551,000 are men. According to Ethiopian Demographic and Health Survey (EDHS) 2011, the coverage of antenatal care (ANC) services, birth assistance by skilled provider, and postnatal care in the city were $93.6 \%, 83.9 \%$, and $47.7 \%$, respectively. ${ }^{8}$

\section{Source and study population}

The source population for this study was all women who were attending PNC follow up at Addis Ababa Gandhi, St. Paul, and Zewditu referral hospitals, Addis Ababa Ethiopia, during data collection time. All randomly selected women who were attending PNC follow up at Gandhi, St. Paul, and Zewditu referral 
hospitals, Addis Ababa Ethiopia, during the study period and those who fulfill the inclusion criteria were the study population.

\section{Inclusion criteria and exclusion criteria}

The inclusion criteria for this study were all postnatal mothers at Addis Ababa health referral hospitals during the study period were included and Mothers who were critically ill during the study and whose gestational age is below 37 weeks (preterm delivery) were excluded from the study.

\section{Sample size determination and sampling procedure}

The sample size was calculated using Epi Info, Stat Calc, and considering 95\% confidence level (Cl) $80 \%$ power, control to case ratio of 2, minimum odd ratio of $2(\mathrm{OR})$, and $10 \%$ non-response gave a minimum sample of 82 cases of adherence and 164 controls.

This study was conducted in three referral hospitals of Addis Ababa, namely Zewditu Memorial Hospital $(\mathrm{ZMH})$, Palouse hospital and Gandhi Memorial Hospital (GMH).the number of participants per hospital was allocated based on the average number of mothers who attend PNC follow up per year. Previous PNC follow up per year for Zewditu Memorial Hospital, Palouse Hospital, Gandhi Memorial Hospital were $2471,2580,974$, respectively. Based on this data and the sample size of the study, the participants of each hospital were selected using a systematic random sampling method with intervals of two.

\section{Operational definition}

Antenatal service: Pregnancy check-up by health personnel, provision of iron/folic acid supplements, tetanus vaccination and health education and counseling.

ANC follow up: A woman who had regular antenatal care four times during pregnancy period.

Cases: For this study, cases are women who took 90+ tablets during pregnancy period

Controls: Controls are women who took less than 90 tablets during their pregnancy period.

Adherence: Mothers are said to be adhered to IFA supplement if they took 90 or more of the supplement, during pregnancy period.

Non-adherence: Pregnant mother is said to be non-adherence to IFA supplement if they took less than 90 tablets during pregnancy period.

Trimester: The number of week during pregnancy (1st, 1-12 weeks, 2nd, 13-26 weeks, 3rd, 27-40 weeks).Gravidity: The number of pregnancy whatever the outcome. 
Parity: The number of live births among pregnancy

Preconception folic acid supplementation: Standard recommendation of folic acid ( $400 \mu \mathrm{g} / \mathrm{day})$ for all women from the moment they begin trying to conceive until 12 weeks of gestation should take folic acid supplements.

Close family member: Are individuals who are related by blood and it includes grandparents, parents, siblings and children.

DDS: Number of food groups consumed in the previous day will be added and Lowest dietary diversity is ( $\leq 3$ food groups), Medium dietary diversity ( 4 and 5 food groups) and High dietary diversity ( $\geq 6$ food groups).

Knowledge: From those knowledge questions asked those who answer less than two answers have poor knowledge and those who answer more than two answers have good knowledge.

\section{Data collection and Analysis}

The data collection instruments were questionnaire contents included socio-demographic, obstetric history, Health facility and knowledge related variables, dietary and nutritional factors, and pre-conception related variables. Women who took more than nighty tablets were considered to have adhered to the supplementation.

The quaternary was pretested on 12 women of similar population at Tikur Anbesa hospital. Data were collected and supervised by six BSc nurses. Both data collectors and supervisors were trained on how to collect the data and how to use the data collection instruments. The supervisors checked the completeness of the data every day.

The collected data were entered, coded and cleaned using Epi DATA version 7.2, and the data management and analysis were performed using SPSS version 20.0 software. Socio-demographic, obstetric, heath faculty and knowledge related variables, dietary and nutritional factors, and preconception related factors of women were presented in text and tables. Bivariate analysis was done and variables with less than $0.25 \mathrm{P}$-values were included in the multiple logistic regression analysis. In the multivariable analysis, predictors with P-value less than 0.05 were considered statically significant.

\section{Results}

\section{Socio-demographic characteristic of study subjects}

A total of 240 postnatal women were interviewed with a response rate of $98 \%$. A majority of the cases $(95 \%)$ and the controls $(90.6 \%)$ were from Addis Ababa. There was no difference between the mean age of cases $(29.13 ; \pm 5.03)$ and controls $(31.36 ; \pm 6.31)(0.193)$ (Table 1$)$. 
Table 1 Socio-demographic and economic characteristics of women who delivered in three referral hospitals of Addis Ababa, July to September 2020 ( $n=240$ ) 


\begin{tabular}{lll}
\hline Variables & Case (\%) & Control (\%) \\
\hline Residence & & \\
Addis Ababa & $79(95)$ & $145(90.6)$ \\
\hline Out of Addis Ababa & $4(5)$ & $15(9.4)$ \\
\hline
\end{tabular}

\begin{tabular}{lll} 
Age of participant (mean; SD) & $29.13 ; \pm 5.03$ & $31.36 \pm 6.31$ \\
\hline $18-23$ & $5(6.3)$ & $17(10.6)$ \\
\hline $24-28$ & $40(50)$ & $36(22.5)$ \\
\hline $29-33$ & $15(18.8)$ & $50(31.3)$ \\
\hline$>34$ & $20(25.1)$ & $57(35.7)$ \\
\hline
\end{tabular}

\begin{tabular}{lll} 
Age of partner (mean; SD) & $34.95 \pm 5.53$ & $38.64 \pm 8.94$ \\
\hline $24-28$ & $8(10)$ & $15(9.4)$ \\
\hline $29-33$ & $28(35)$ & $33(20.6)$ \\
\hline $34-40$ & $33(41.3)$ & $55(34.4)$ \\
\hline $41-45$ & $7(8.8)$ & $38(23.8)$ \\
\hline$>45$ & $4(5)$ & $1911.9)$
\end{tabular}

Mother able to read and write

\begin{tabular}{lll}
\hline Yes & $79(98.8)$ & $150(93.8)$ \\
\hline No & $1(1.3)$ & $10(6.3)$
\end{tabular}

Highest grade completed

\begin{tabular}{lll}
\hline Primary school & $16(20)$ & $29(18.1)$ \\
\hline Secondary school & $43(53.8)$ & $64(40)$ \\
\hline Above secondary & $20(25)$ & $49(30.6)$
\end{tabular}

Occupation

\begin{tabular}{lll}
\hline Government employee & $21(26.3)$ & $34(21.3)$ \\
\hline Non-government employee & $15(18.8)$ & $31(19.4)$ \\
\hline Business women & $13(16.3)$ & $19(11.9)$ \\
\hline Daily laborer & $3(3.8)$ & $7(4.4)$ \\
\hline Student & $1113.8)$ & $29(18.1)$ \\
\hline House wife & $17(21.3)$ & $40(25)$ \\
\hline
\end{tabular}

Partner able to read and write 


\begin{tabular}{lll} 
Yes & $78(97.5)$ & $145(92.5)$ \\
\hline No & $1(2.5)$ & $3(2)$ \\
\hline
\end{tabular}

\begin{tabular}{lll} 
Partner highest grade completed & & \\
\hline Primary school & $7(8.8)$ & $29(18.1)$ \\
\hline Secondary school & $39(48.8)$ & $73(45.6)$ \\
\hline Above secondary & $34(42.5)$ & $58(36.3)$ \\
\hline
\end{tabular}

\begin{tabular}{lll} 
Partner occupation & & \\
\hline Government employee & $18(22.5)$ & $35(21.9)$ \\
\hline Non-government employee & $28(35)$ & $43(26.9)$ \\
\hline Businessman & $20(25)$ & $44(27.5)$ \\
\hline Daily laborer & $7(8.8)$ & $21(13.1)$ \\
\hline Farmer & $1(7.5)$ & $13(8.1)$ \\
\hline Jobless & $6(7.5)$ & $4(2.5)$ \\
\hline
\end{tabular}

\begin{tabular}{lll} 
Age at marriage (mean; SD) & $24.29 ; 4.35$ & $24.20 ; 4.6$ \\
\hline $15-24$ & $49(61.3)$ & $74(46.3)$ \\
\hline $25-34$ & $47(33.8)$ & $61(38.1)$ \\
\hline$\geq 35$ & $4(5)$ & $18(11.3)$ \\
\hline
\end{tabular}

\begin{tabular}{lll} 
Family size & & \\
\hline$\leq 5$ & $77(96.3)$ & $149(93.1)$ \\
\hline$>5$ & $3(3.8)$ & $11(6.9)$ \\
\hline
\end{tabular}

\begin{tabular}{lll} 
Income & $6(7.5)$ & $18(11.3)$ \\
\hline $500-1000$ & $8(10)$ & $28(17.5)$ \\
\hline $1001-2000$ & $66(82.5)$ & $114(71.3)$ \\
\hline$>2001$ & 66 \\
\hline
\end{tabular}

\section{Obstetric history of participants}

There was no difference between the cases and controls in terms of history of abortion, stillbirth, and mean age of mothers when they give birth for the first time. Regarding gravidity and parity, $65 \%$ of the cases and $80.6 \%$ of controls were Multigravida, and $46.3 \%$ of the cases and $33.8 \%$ of the controls were Primiparous (Table 2). 
Table 2 Obstetric histories of women who delivered in three referral hospitals of Addis Ababa, July to September $2020(n=240)$ 


\begin{tabular}{lll}
\hline Variables & Case (\%) & Control (\%) \\
\hline Age give birth first time (mean; SD) & $24.81 \pm 4.441$ & $25.09 \pm 4.659$ \\
$15-24$ & $44(55)$ & $64(40)$ \\
\hline $25-34$ & $31(38.8)$ & $92(57.5)$ \\
$\geq 35$ & $5(6.3)$ & $4(2.5)$ \\
\hline
\end{tabular}

Gravidity

\begin{tabular}{|c|c|c|}
\hline Primigravida & $28(35)$ & 31 (19.4) \\
\hline Multigravida & 52 (65) & 129 (80.6) \\
\hline
\end{tabular}

Parity

\begin{tabular}{lll}
\hline Primiparous & $37(46.3)$ & $54(33.8)$ \\
\hline Multiparous & $43(53.8)$ & $106(66.3)$
\end{tabular}

Previous history of abortion

\begin{tabular}{lll}
\hline Yes & $21(26.3)$ & $49(30.6)$ \\
\hline No & $59(73.8)$ & $111(69.4)$
\end{tabular}

Still birth history

\begin{tabular}{lll}
\hline Yes & $3(3.8)$ & $19(11.9)$ \\
\hline No & $77(96.3)$ & $141(88.1)$
\end{tabular}

Attend ANC

\begin{tabular}{lll}
\hline Yes & $77(96.3)$ & $139(86.9)$ \\
\hline No & $3(3.8)$ & $21(13.1)$
\end{tabular}

Number of visit

\begin{tabular}{lll}
$\leq 4$ & $51(63.8)$ & $128(80)$ \\
\hline$>4$ & $29(36.3)$ & $32(20)$
\end{tabular}

ANC initiation time

\begin{tabular}{lll} 
First trimester & $58(72.5)$ & $43(26.9)$ \\
\hline Second trimester & $22(27.5)$ & $117(73.1)$
\end{tabular}

Place of delivery to the last pregnancy

Home

$12(15) \quad 45(28.8)$ 


\begin{tabular}{lll} 
Public hospital & $43(53.8)$ & $80(50)$ \\
\hline Health post & $21(26)$ & $24(15)$ \\
\hline Private hospital & $4(5)$ & $11(6.9)$ \\
\hline
\end{tabular}

Last delivery assistant

\begin{tabular}{lll} 
Female relative & $10(12.5)$ & $13(8.1)$ \\
\hline Health extension worker & $41(51.3)$ & $70(43.8)$ \\
\hline Health professional & $25(31.3)$ & $67(41.9)$ \\
\hline Nobody & $4(5)$ & $10(6.3)$
\end{tabular}

PNC follow-up

\begin{tabular}{lll}
\hline Yes & $36(45)$ & $60(37.5)$ \\
\hline No & $44(55)$ & $100(62.5)$ \\
\hline
\end{tabular}

Heard about modern contraceptive

\begin{tabular}{lll}
\hline Yes & $54(67.5)$ & $99(61.9)$ \\
\hline No & $26(32.5)$ & $61(38.1)$ \\
\hline
\end{tabular}

Information source about contraceptive

\begin{tabular}{lll}
\hline Health worker & $14(17.5)$ & $24(15)$ \\
\hline Mass media & $26(32.5)$ & $52(32.5)$ \\
\hline Friends & $5(6.3)$ & $24(15)$ \\
\hline Health extension worker & $9(11.3)$ & $36(22.5)$ \\
\hline
\end{tabular}

Partners help to attend ANC

\begin{tabular}{lll}
\hline Yes & $39(48.8)$ & $77(48.1)$ \\
\hline No & $41(51.3)$ & $83(51.9)$
\end{tabular}

Partners help to decide where give birth

\begin{tabular}{lll} 
Yes & $44(55)$ & $74(46.3)$ \\
\hline No & $36(45)$ & $86(53.8)$ \\
\hline
\end{tabular}

Morning sickness

\begin{tabular}{lll}
\hline Yes & $28(35)$ & $107(66.9)$ \\
\hline No & $52(65)$ & $13(33.1)$ \\
\hline
\end{tabular}




\section{Preconception characteristics of the study participants}

Out of the total participants, $81.3 \%$ of the cases and $60.6 \%$ of the controls have planned pregnancy, which shows a statistically significant difference. However, the majority of the controls [61.3\%] and less than half of the cases [48.8\%] use modern contraceptive right before conception. Moreover, there was no difference in their knowledge of where family planning is found and chronic illness before conception (Table 3).

Table 3 Preconception characteristics of women who delivered in three referral hospitals of Addis Ababa, July to September 2020( $n=240)$

\begin{tabular}{lll}
\hline Variables & Case (\%) & Control (\%) \\
\hline Use modern contraceptive & & \\
Yes & $39(48.8)$ & $9(61.3)$ \\
\hline No & $41(51.3)$ & $61(38.8)$ \\
\hline
\end{tabular}

Know were family planning found

\begin{tabular}{lll}
\hline Yes & $38(47.5)$ & $107(66.9)$ \\
\hline No & $12(15)$ & $24(15)$
\end{tabular}

Chronic illness before conception

\begin{tabular}{lll} 
Yes & $6(7.5)$ & $30(18.8)$ \\
\hline No & $74(92.5)$ & $130(81.3)$
\end{tabular}

Current pregnancy type

Planned 65 (81.3) 97 (60.6)

Unplanned $15(18.8) \quad 63(39.4)$

\section{Knowledge and health facility-related characteristics of study participants}

The majority of the study participants, [68.8\%] cases and [78.1\%] controls, have poor knowledge on ironfolic acid supplementation. Prevention of maternal death $28.2 \%$ [ $13.8 \%$ cases and $14.4 \%$ controls], preventing infant mortality $31.9 \%$ [ $20 \%$ cases and $11.9 \%$ controls], prevention of birth defects $15 \%$ [ $12.5 \%$ cases and $2.5 \%$ controls], and give strength to the mother $10.6 \%$ [ $7.5 \%$ cases and $3.1 \%$ controls] were among the benefits of IFAS use indicated by the participants (Table 4).

Table 4 Knowledge and health-facility related characteristics of women who delivered in three referral hospitals of Addis Ababa, July to September $2020(n=240)$ 


\begin{tabular}{lll}
\hline Variables & Case (\%) & Control (\%) \\
\hline Distance to health facility & & \\
$\leq 30$ minutes & $31(38.8)$ & $21(13.3)$ \\
\hline 30 minutes & $49(61.3)$ & $139(86.9)$ \\
\hline
\end{tabular}

Waiting time

\begin{tabular}{lll}
\hline$\leq 30$ minutes & $40(50)$ & $40(25)$ \\
\hline$>30$ minutes & $40(50)$ & $120(75)$
\end{tabular}

Distance to source of contraceptive

\begin{tabular}{lll}
$\leq 30$ minutes & $44(55)$ & $57(35.6)$ \\
\hline$>30$ minutes & $36(45)$ & $103(64.4)$
\end{tabular}

Counseling on IFAS

\begin{tabular}{lll}
\hline Yes & $49(61.3)$ & $50(31.3)$ \\
\hline No & $31(38.8)$ & $110(68.8)$
\end{tabular}

Encounter shortage of supplement

\begin{tabular}{lll}
\hline Yes & $26(32.5)$ & $71(44.4)$ \\
\hline No & $54(67.5)$ & $89(55.6)$
\end{tabular}

Knowledge

\begin{tabular}{lll}
\hline Good & $25(31.3)$ & $35(21.9)$ \\
\hline Poor & $55(68.8)$ & $125(78.1)$
\end{tabular}

Benefit of IFAS

\begin{tabular}{lll} 
Prevent maternal death & $11(13.8)$ & $23(14.4)$ \\
\hline Prevent infant mortality & $16(20)$ & $19(11.9)$ \\
\hline Prevent birth defects & $10(12.5)$ & $4(2.5)$ \\
give strength to the mother & $6(7.5)$ & $5(3.1)$
\end{tabular}

Risk of IFAS

\begin{tabular}{lll} 
Harm fetus growth & $3(3.8)$ & $9(5.6)$ \\
\hline Cause bigger fetus & $14(17.5)$ & $38(23.8)$ \\
\hline Result in complicated delivery & $1(1.3)$ & $10(6.3)$ \\
\hline
\end{tabular}




\section{Nutritional characteristics of the study participants}

More than half of the respondents [53.8\% cases and $60 \%$ controls] did not take additional food during pregnancy (Table 5).

Table 5 Nutritional characteristics of women who delivered in three referral hospitals of Addis Ababa, July to September 2020 ( $n=240$ )

\begin{tabular}{lll}
\hline Variables & Case (\%) & Control (\%) \\
\hline Additional food during pregnancy & $37(46.3)$ & $64(40)$ \\
Yes & $43(53.8)$ & $96(60)$ \\
\hline No & & \\
& & \\
\hline Meal frequency & $25(31.3)$ & $32(20)$ \\
\hline More than three times & $28(35)$ & $73(45.6)$ \\
\hline Three times & $19(23.8)$ & $48(30)$ \\
\hline Two times & $8(10)$ & $7(4.4)$ \\
\hline One time & &
\end{tabular}

Tea or coffee after meal

\begin{tabular}{lll}
\hline Yes & $37(46.3)$ & $59(36.9)$ \\
\hline No & $43(53.8)$ & $101(63.1)$
\end{tabular}

Partner encourage to eat additional food

\begin{tabular}{lll} 
Yes & $51(63.8)$ & $80(50)$ \\
\hline No & $29(36.3)$ & $80(50)$
\end{tabular}

\section{Dietary diversity score among participant mothers}

About $51.25 \%$ of the cases and $67.5 \%$ of controls had low dietary diversity score.

\section{Factors associated with adherence to IFAS}

Age of participants, ANC initiation time, gravidity, whether they get counseling on IFG or not, time taken to travel to health facility and whether the pregnancy was planned or not were independent predictors of adherence to IFA supplementation. 
Women who are in the age group 29-33 are 1.6 times more likely [AOR=1.66, 95\% Cl: 2.010-0.0492] to adhered IFG supplementation than mothers who are in the age group age forte and ab. Women who had planned pregnancy were 4 times more likely $[\mathrm{AOR}=4.2,95 \% \mathrm{Cl}: 1.6-10.9]$ to adhere as compared to unplanned pregnancy.

Women who started there ANC follow-up in the first trimester are 4 times more likely [AOR=4.21,95\% Cl: 2.3-10.66] to adhere than those who started ANC follow up in the second trimester.

In addition to the above factors, women who travel less than 30 minutes to reach to the health facility have 3.17 times more likely [AOR=3.17,95\% $\mathrm{Cl}: 1.35-7.4]$ to adhere IFA supplement than those who travel more than 30 minutes to reach to the health facility.

More over women who had counseling on IFAS are almost 4 times more likely [AOR, $=3.89,95 \% \mathrm{Cl}: 1.8-8.4]$ to adhere IFAS and women who are in Primigravida are 2 times more likely [AOR=2.08, 95\% Cl: 1.06-4.09] to adhere than Multigravida mothers. Women who had morning sickness during pregnancy are 0.33 times less likely [AOR=0.33, 95\% Cl: $0.15-0.69$ ] to adhere than women without morning sickness (Table 6).

Table 6 Multivariable logistic regression model predicting adherence to iron-folic acid supplementation, women who delivered in Addis Ababa referral hospitals, Ethiopia, July to September $(n=240)$ 


\begin{tabular}{|c|c|c|c|c|c|c|}
\hline \multirow[t]{2}{*}{ Predictors } & \multirow[t]{2}{*}{ Case } & \multirow[t]{2}{*}{ Control } & \multirow[t]{2}{*}{ COR } & \multirow[t]{2}{*}{$\mathrm{AOR}$} & \multicolumn{2}{|c|}{$95 \%$ CI } \\
\hline & & & & & Lower & Upper \\
\hline \multicolumn{7}{|l|}{ Age } \\
\hline $18-23$ & $5(6.3)$ & $17(10.6)$ & 0.838 & 0.453 & 0.038 & 5.361 \\
\hline $24-28$ & $40(50)$ & $30(36)$ & 3.167 & 0.563 & 0.087 & 3.626 \\
\hline $29-33$ & $15(18.8)$ & $50(31.3)$ & 0.855 & 1.669 & 2.010 & 0.0492 \\
\hline$>34$ & $20(25.1)$ & $57(35.7)$ & 1 & 1 & & \\
\hline
\end{tabular}

ANC initiation time

\begin{tabular}{lllcccc}
\hline First trimester & $58(72.5)$ & $43(26.9)$ & 7.173 & 4.21 & 2.3 & 10.66 \\
\hline Second trimester & $22(27.5)$ & $117(73.1)$ & 1 & 1 & & \\
\hline
\end{tabular}

Counseling on IFAS

\begin{tabular}{lllcccc}
\hline Yes & $49(61.3)$ & $50(31.3)$ & 0.28 & 3.89 & 1.8 & 8.42 \\
\hline No & $31(38.8)$ & $110(68.8)$ & 1 & 1 & & \\
\hline
\end{tabular}

\begin{tabular}{lllcccc} 
Gravidity & & & & & & \\
Primigravida & $52(35)$ & $31(19.4)$ & 2.24 & 2.08 & 1.06 & 4.09 \\
\hline Multigravida & $28(65)$ & $129(80.6)$ & 1 & 1 & & \\
\hline
\end{tabular}

Pregnancy type

\begin{tabular}{lcccccc}
\hline Planned & $65(81.3)$ & $97(60.6)$ & 3.505 & 4.2 & 1.6 & 10.9 \\
\hline Unplanned & $15(18.8)$ & $63(39.4)$ & 1 & 1 & & \\
\hline
\end{tabular}

Distance to health facility

\begin{tabular}{lllcccc}
\hline$\leq 30$ minutes & $31(38.8)$ & $21(13.3)$ & 1.181 & 3.17 & 1.37 & 7.4 \\
\hline >30 minutes & $49(61.3)$ & $139(86.9)$ & 1 & 1 & &
\end{tabular}

Morning sickness

\begin{tabular}{lcccccc}
\hline Yes & $28(35)$ & $107(66.9)$ & 0.267 & 0.33 & 0.15 & 0.69 \\
\cline { 1 - 4 } No & $52(65)$ & $13(33.1)$ & 1 & 1 & & \\
\cline { 1 - 4 }
\end{tabular}

\section{Discussion}

Age of participants, ANC initiation time, gravidity, counseling on iron-folic acid supplementation, time taken to travel to the health facility, and planned pregnancy were significantly associated with adherence to IFAS. 
According to this study, pregnant women in age group of 29-33 years were 1.6 times more likely to adhered IFAS compared to mothers who were in age group forte and above. This study is in line with other cross-sectional studies conducted in northwestern zone of Tigray region in Ethiopia. ${ }^{9}$ This might be due to the fact that most of the women in this age group are Primigravida so that they will follow the guideline much better to insure good pregnancy outcome.

This study also reveals that early registration for ANC follow-up has statistically significant difference compared to late registration after the second trimester. The result of this finding is consistent with different studies conducted in Tigray region in Ethiopia and in India. ${ }^{9,10}$ This might be because of pregnant women who have registered early for ANC service and got repeated counseling have a chance to finish the recommended number of supplement.

In addition to the above factors, gravidity is one of the main associated variables found in our study with IFAS were Primigravida mothers are two times more likely to adhere than Multigravida mothers. This result is also supported by a study conducted in Jida district in Ethiopia, Urban-Slam in India, and Kiambu Country in Kenya. 4,5,11 This is because mothers are very careful during the first pregnancy to follow the guideline and advice given to finish the IFAS to insure a successful pregnancy.

Moreover, this study highlighted that getting counseling on IFAS during pregnancy period helps to ensure adherence level. This finding is in line with other studies conducted in Jida district, North Wollo zone and Afar region in Ethiopia, and also in Senegal. ${ }^{11-14}$ This is because of women who get better counseling on IFAS may have a good understanding and knowledge on how and for how long to take the supplement for insuring maternal health and good pregnancy outcome.

Another factor that has a significant association with IFAS is the time taken to reach to the health facility. The finding of this study reveals that women who travel less than 30 minutes to reach the health facility are 3.17 times more likely to adhere compared to those who travel more than 30 minutes. This result is inconsistent with the study conducted in Aykel town, northwest Ethiopia. ${ }^{15}$ Geographic distance to health facilities could affect women's access to ANC services and therefore affect access to IFAS. ${ }^{16}$ But, the finding of the current study is not in agreement with another study conducted in Afar region of Ethiopia. ${ }^{14}$ This may-be because this study is conducted in referral hospitals of Addis Ababa, mothers may not get easy access to reach to the hospitals which will be a problem to get proper follow up to insure adherence of IFAS.

In addition to the above factors, pregnant mothers who have morning sickness are $67 \%$ less likely to adhere to taking IFAS than pregnant mothers who do not have morning sickness. This may be due to the fact that experiencing morning sickness is a major side effect not to take the IFAS. The most common reason was the belief that the supplement had either cause or contributes to morning sickness. ${ }^{17}$

Furthermore, this study revealed that planned pregnancy has a better outcome for IFAS adherence than unplanned pregnancy. This may be because whenever mothers plan for the pregnancy there is high 
chance of starting follow up early and getting better chance and enough time to adhere the supplement.

\section{Limitation Of The Study}

Even though it is not unique for these study limitations of the study is that information on adherence rate was from self-report of taking tablets.

\section{Conclusion And Recommendation}

This study highlighted a number of important findings that influence adherence of IFAS. Early registrations for ANC service, planned pregnancy, and distance to the health facility, gravidity, age, and morning sickness were found significantly associated with adherence to taking IFAS. IFAS should be available at all levels of care and in the form of suitable and with fewer side effects. Moreover, focus should be given on developing good practice guideline strategies to improve IFAS adherence. Counseling should be given for clients on the correct dosage and duration of supplementation for prevention of anemia and neural tube defects. Health care providers of maternal and neonatal care should give more attention for Multigravida mother's iron-folic acid supplementation during pregnancy and the postpartum period.

\section{Abbreviations}

ANC, antenatal care; PNC, postnatal care; WHO, world health organization.

\section{Declarations}

\section{Data sharing statement}

The datasets used and/or analyzed during the current study are available from the corresponding author on reasonable request.

\section{Ethical approval and consent to participate}

The ethical issue of this study was approved by the ethical committee of Jimma University, department of nutrition and dietetics and official permission to undertake the study was obtained from the hospitals. The supportive staffs (i.e. card office, ANC clinic was informed about the purpose of the study and verbal consent was obtained. Confidentiality of patient's information was assured and information recorded anonymously.

\section{Acknowledgments}

We would like to thank the nutrition and dietetics department of Jimma University, for their support and cooperation. Finally, we would like to acknowledge the data collectors, supervisors and participants for their unreserved cooperation. 
Author contribution

Tigist Alemu Taye, Melese Sinaga, and Abonsh Taye have substantial contribution on the conception, design analysis and interpretation of results. All authors read and approved the final manuscript.

\section{Disclosure}

The authors report no conflict of interest in this work.

\section{Funding}

The authors declare that there was no funding source.

\section{References}

1. Nisar YB, Dibley MJ, Mir AM. Factors associated with non-use of antenatal iron and folic acid supplements among Pakistani women: a cross sectional household survey. BMC pregnancy and childbirth. 2014;14(1):305.

2. Haidar J, Melaku U, Pobocik R. Folate deficiency in women of reproductive age in nine administrative regions of Ethiopia: an emerging public health problem. South African Journal of Clinical Nutrition. 2010;23(3):132-7.

3. Fiedler JL DAA, Sununtnasuk C. A simple method for making a rapid, initial assessment of the consumption and distribution of iron-folic acid supplements among pregnant women in developing countries. 2011 1; 54.

4. Mithra P, Unnikrishnan B, Rekha T, Nithin K, Mohan K, Kulkarni V, et al. Compliance with iron-folic acid (IFA) therapy among pregnant women in an urban area of south India. African health sciences. 2014;14(1):255-60.

5. Kamau MW, Mirie W, Kimani S. Compliance with Iron and folic acid supplementation (IFAS) and associated factors among pregnant women: results from a cross-sectional study in Kiambu County, Kenya. BMC public health. 2018;18(1):1-10.

6. Demographic E. Health survey central statistical agency Addis Ababa. Ethiopia ICF International Calverton, Maryland, USA. 2011:180-6.

7. Debele MG. Design of DC power distribution system using hybrid power (wind and solar) for Ethiopian Ministry of Science and Technology data center

8. Gebremedhin S. Trend and socio-demographic differentials of Caesarean section rate in Addis Ababa, Ethiopia: analysis based on Ethiopia demographic and health surveys data. Reproductive health. 2014;11(1):14.

9. Gebre A, Mulugeta A, Etana B. Assessment of factors associated with adherence to iron-folic acid supplementation among urban and rural pregnant women in North Western Zone of Tigray, Ethiopia: comparative Study. International Journal of Nutrition and Food Sciences. 2015;4(2):161. 
10. Dutta AJ, Patel P, Bansal R. Compliance to iron supplementation among pregnant women: a cross sectional study in urban slum. Natl J Community Med. 2014;5(4):457-62.

11. Gedefa GY, Demissie HF, Amare YW, Rameto AJ. Assessment of Adherence to Iron-Folic Acid Supplementation and Associated Factor Among Pregnant Women in Jida District, Ethiopia. International Journal of Nursing and Health Science. 2019;6(3):16.

12. Demis A, Geda B, Alemayehu T, Abebe H. Iron and folic acid supplementation adherence among pregnant women attending antenatal care in North Wollo Zone northern Ethiopia: institution based cross-sectional study. BMC research notes. 2019;12(1):107.

13. Niang K, Faye A, Tine JAD, Diongue FB, Ndiaye B, Ndiaye MB, et al. Determinants of iron consumption among pregnant women in southern Senegal. Open Journal of Obstetrics and Gynecology. 2016;7(1):41-50.

14. Gebre A, Debie A, Berhane A, Redddy PS. Determinants of compliance to iron-folic acid supplementation among pregnant women in pastoral communities of Afar region: the cases of Mille and Assaita Districts, Afar, Ethiopia-2015. Medico Res Chronicles. 2017;4:352-62.

15. Assefa H, Abebe SM, Sisay M. Magnitude and factors associated with adherence to Iron and folic acid supplementation among pregnant women in Aykel town, Northwest Ethiopia. BMC pregnancy and childbirth. 2019;19(1):296.

16. Wang W, Benedict R, Mallick L. The Role of Health Facilities in Supporting Adherence to Iron-folic Acid in Haiti and Malawi: A Study Linking Health Facility Survey and Population Survey Data. 2020.

17. Barbour RS, Macleod M, Mires G, Anderson AS. Uptake of folic acid supplements before and during pregnancy: focus group analysis of women's views and experiences. Journal of Human Nutrition and Dietetics. 2012;25(2):140-7.

\section{Figures}




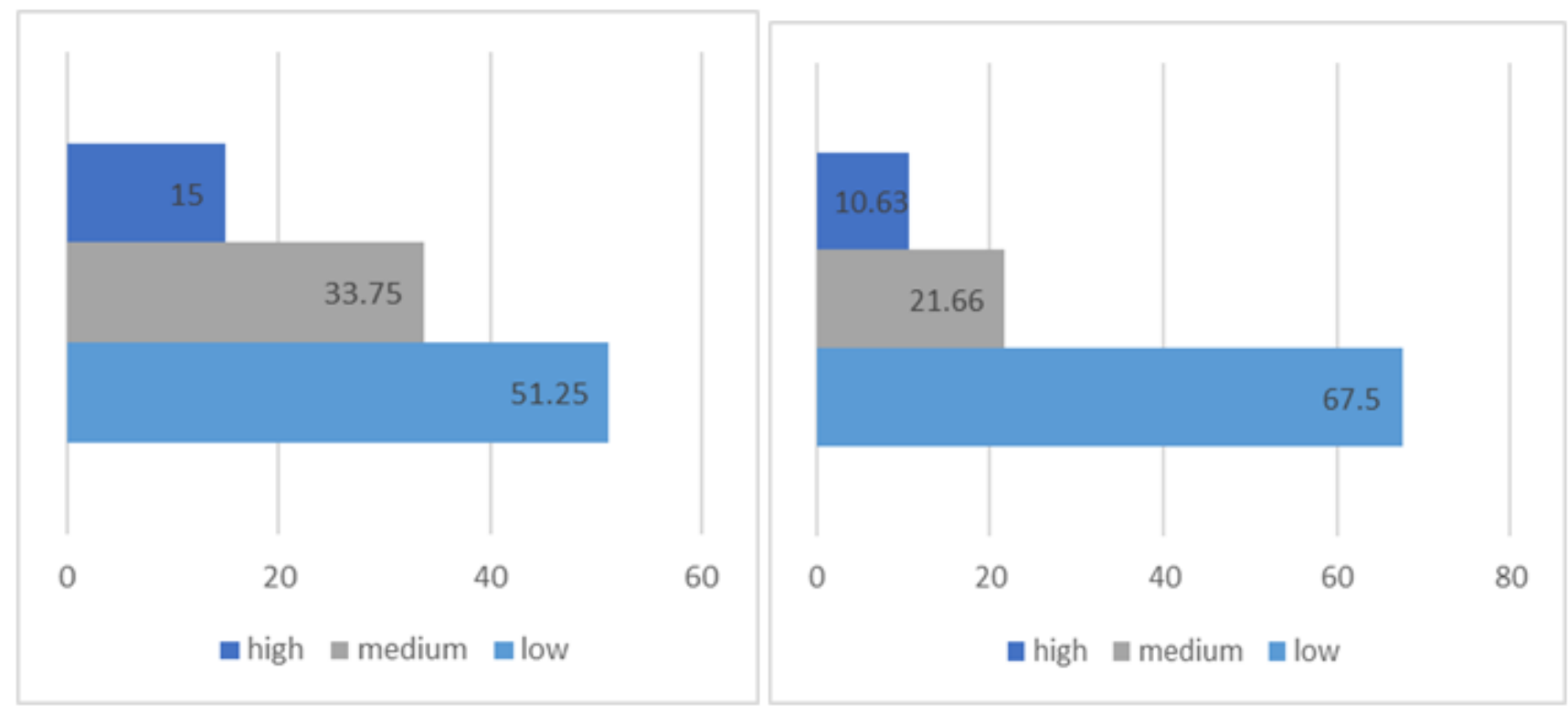

(a)

(b)

\section{Figure 1}

Dietary diversity score among participant mothers of cases (a) and controls (b), Addis Ababa referral hospitals, Ethiopia, July 15 to September 15, $2020(n=240)$. 